\title{
Erratum to: Changes of vitellogenin and Lipase in captive Sterlet sturgeon Acipenser ruthenus females during previtellogenesis to early atresia
}

\author{
Sobhan Ranay Akhavan - Amir Parviz Salati • \\ Bahram Falahatkar - Seyed Amir Hossein Jalali
}

Published online: 6 April 2016

(C) Springer Science+Business Media Dordrecht 2016

\section{Erratum to: Fish Physiol Biochem DOI 10.1007/s10695-015-0189-8}

Unfortunately, one of the co-author's affiliation and formulas (Seyed Amir Hossein Jalali) were published incorrectly in the original publication of the article. The corrected affiliation of the author and the formulas are provided here.

The online version of the original article can be found under doi:10.1007/s10695-015-0189-8.

S. R. Akhavan · A. P. Salati $(\square)$

Department of Fisheries, Faculty of Marine Natural Resources, Khorramshahr University of Marine Science and Technology, Khorramshahr, Iran e-mail: apsalati@kmsu.ac.ir

B. Falahatkar Fisheries Department, Faculty of Natural Resources, University of Guilan, P.O. Box 1144, Sowmeh Sara, Guilan, Iran

\section{S. A. H. Jalali}

Department of Natural Resources, Isfahan University of Technology, Isfahan 84156-83111, Iran

\section{S. A. H. Jalali}

Institute of Biotechnology and Bioengineering, Isfahan

University of Technology, Isfahan 84156-83111, Iran
Formulas in real-time polymerase chain reaction are not in correct format. The corrected format is given below:

$$
\begin{aligned}
& \left(\Delta \mathrm{Ct}=\mathrm{Ct}_{\text {target gene }}-\mathrm{Ct}_{\text {reference gene }}\right) \\
& \left(\Delta \mathrm{Ct}_{\text {target }}-\Delta \mathrm{Ct}_{\text {calibrator }}\right) \\
& 2^{-\Delta \Delta \mathrm{Ct}}
\end{aligned}
$$

